
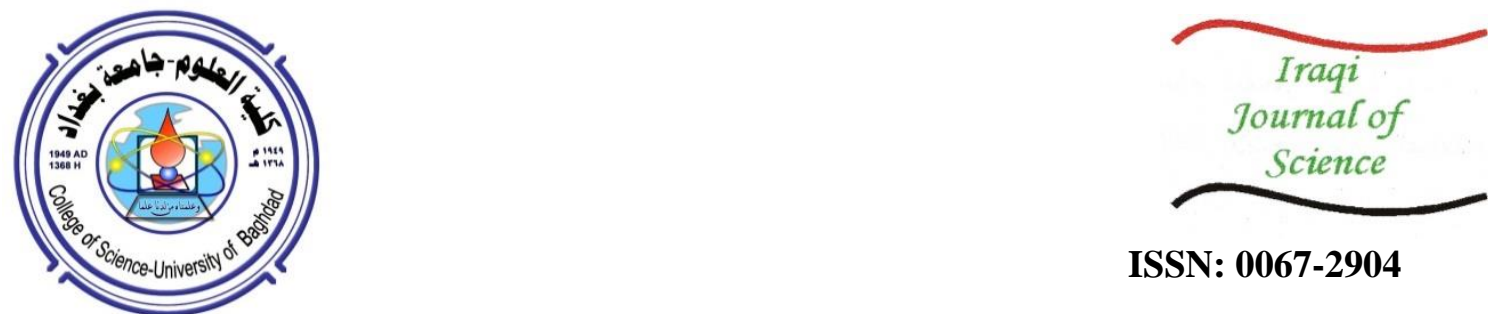

ISSN: 0067-2904

\title{
Impacts of Androgen Abuse and Overtraining on Endocrine Profile in Bodybuilders
}

\author{
Ekhlas Abdallah Hassan $^{1}$, Rusul Y. Hameed ${ }^{2}$, Sabreen Ali Mezil ${ }^{3}$ \\ ${ }^{1}$ Department of Chemistry, College of Science, University of Diyala, Baquba, Diyala, Iraq \\ ${ }^{2} \mathrm{Al}$ Hikma College University, Bagdad, Iraq \\ ${ }^{3}$ Department of medical Instrumentation engineering, Al-Hadi University Collage ,Baghdad, Iraq
}

Received: $21 / 6 / 2021$

Accepted: 7/9/2021

\begin{abstract}
Abuse of androgens and overtraining expose bodybuilders to multifactorial stress influences related to endocrine activity. Endocrine responses in 23 bodybuilder athletes were investigated after a strength training period, during which they were taking high doses of androgenic-anabolic steroids. Serum concentrations of TSH, T3, and T4 were unchanged significantly. Serum LH and FSH concentrations decreased dramatically $(P<0.05)$. In addition, low mean concentration of serum testosterone was recorded, with more substantial reduction in participants of elder ages. The multiple regression model used in this analysis supported this inference. On the other hand, a positive association was observed between levels of blood lipids (total cholesterol, triglyceride) and the outcome predictor (mean serum testosterone level). The results also suggested a negative correlation between testosterone level and each of age and HDL level. The current study shows that excessive bodybuilding exercise has an impact on the hypothalamic-pituitarythyroid (HPT) axis in top-level athletes. Also, simultaneous usage of anabolic steroids induces extreme shifts in the hypothalamic-pituitary-gonadal (HPGA) axis, which is reflected as changes in testosterone level, development of the overtraining syndrome, and adverse influences on hormonal control.
\end{abstract}

Keywords: Androgens, Bodybuilders athletes, Testosterone hormones, Thyroid hormone, Follicle-stimulating hormone Luteinizing Hormone.

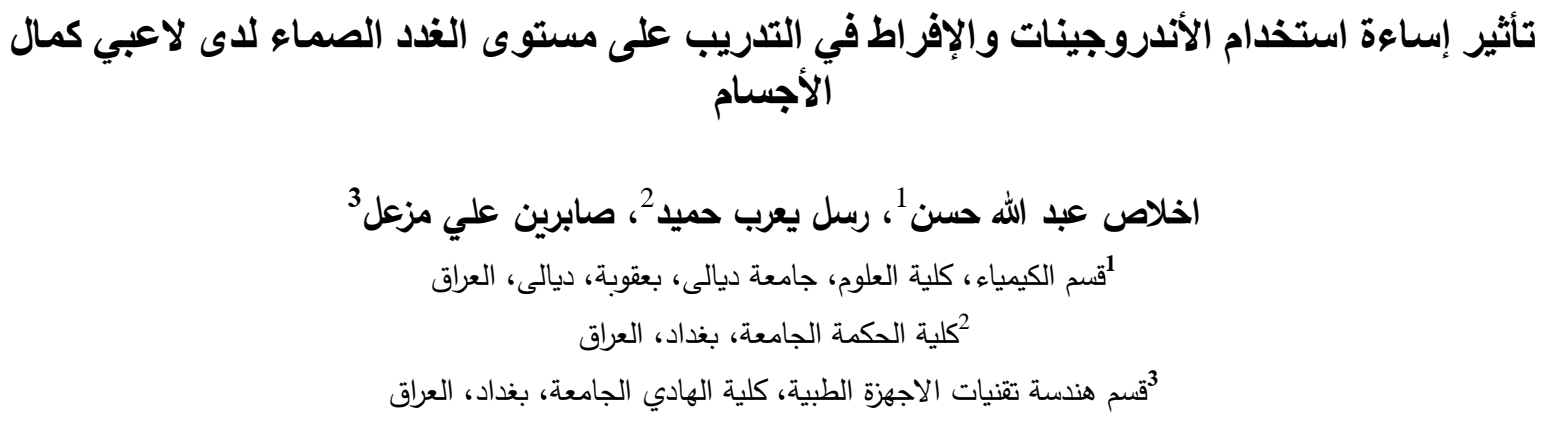

*Email: dpmdevicesb@huc.edu.iq 


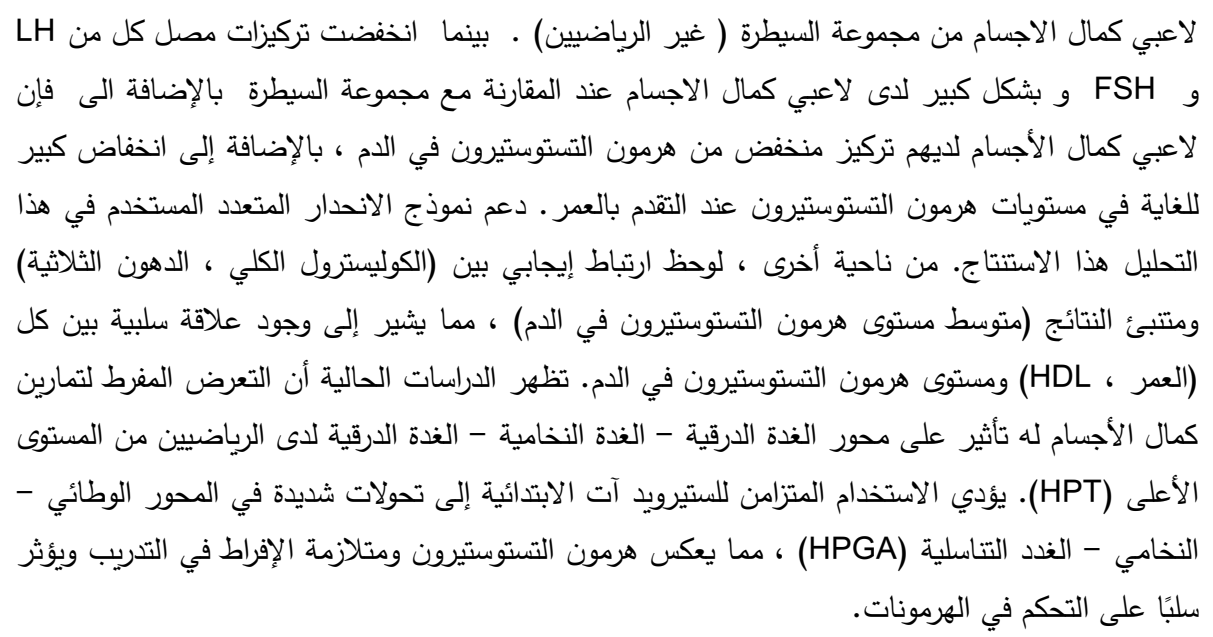

\section{Introduction}

Exercise has been found to affect the function of multiple glands as well as the development of their hormones [1]. Gonadotropes in the anterior pituitary gland manufacture and release hormones called follicle-stimulating hormone (FSH) and luteinizing hormone (LH) [2]. In addition, both triiodothyronine (T3) and thyroxine (T4) are thyroid hormones, with the former playing a number of essential functions in metabolism, heart rate, digestion, muscle control, brain function and development, and bone health [3]. Hormonal balance under stress has been shown to be affected by a variety of factors, including training load and dietary deficiencies [4-6]. The impact of long-term physical exercise on hormonal response in athletes has been well documented. Low testosterone, FSH , and LH levels, as well as elevated levels of thyroid hormone-binding proteins have been related to these symptoms in the HPGA and HPT axes [4,7]. Overtraining is well-known to be associated with testosterone deficiency [4]. Cortisol levels have been linked to low testosterone levels in over trained athletes. In addition, overtraining has been shown to suppress testosterone output in men [8]. Resistance exercise can temporarily increase testosterone and has an effect on fat distribution in women [9]. The regular exercise raises testosterone levels more than weight loss, according to Kumagai's survey on obese men [10].

Bodybuilders use a variety of tools, including dietary supplements and anabolic-androgenic steroids (AASs), in addition to exercise and nutrition, to achieve their optimal body structure [11-13]. Androgenic hormones, such as testosterone derivatives, are known as AASs. Supraphysiological testosterone increases stimulate protein synthesis, which leads to increased muscle size, density, and strength [14]. However, it has been clinically proven that it leads them to elevated acne, fluid accumulation, and an increase in androgenic hormones, which increases breast size and the risk of breast cancer. It also leads to reduced testicle size and sperm count, as well as neurological problems in men and menstrual irregularities, clitoromegaly, and masculinization in women [15]. Very limited data on endocrine profiles in bodybuilders are published. The aim of the study is to examine these differences in endocrine profiles in more detail and to interpret some of the findings.

\section{Materials and methods}

\section{Subjects}

Twenty-three male bodybuilders $(23.00 \pm 1.78$ years old; $174.36 \pm 6.24 \mathrm{~cm}$ height; $66.58 \pm$ $5.76 \mathrm{~kg}$ weight) from Diyala province, east Iraq, were selected as a treatment group. They started to practice bodybuilding for approximately four years from the date of conducting the research, and the time elapsed for their use of androgens was approximately 2.5-3 years. Fifteen male healthy age-matched, non-smoker, non-drinker individuals (22.00 \pm 1.98 years; $(176.36 \pm 4.21 \mathrm{~cm}$ height; $68.50 \pm 4.56 \mathrm{~kg}$ weight) served as a control group. 
Venipuncture with $5 \mathrm{ml}$ plastic syringes was used to extract fasting blood samples in a resting state. The blood was allowed to to clot at room temperature and centrifuged for 15 minutes at $3000 \mathrm{rpm}$. All serum aliquots were arranged in duplicates for the estimation of cholesterol [16], triglyceride[17], and high density lipoprotein [18] by enzymatic methods. Friedewald's formula was used to calculated levels of low density lipoprotein and very low density lipoprotein [19]. In addition, levels of total testosterone [20], triiodo- thyronine, thyroxin, thyroid stimulating hormone[21], luteinizing hormone [22], and follicle stimulating hormone [23] were measured using the enzyme-linked immunosorbent assay (ELISA). All measurements within the experiments were made in the laboratories of the College of Science / University of Diyala.

\section{Statistical analysis}

Data were expressed as mean $\pm \mathrm{SE}$. The differences in groups were determined by performing Pearson chi-square statistic test and one-way analysis of variance (ANOVA). The differences with a $p$-value $\leq 0.05$ were considered to be statistically significant. Multiple regression models were used to study the independent and net effects of a set of independent (explanatory) variables on the response (dependent or outcome) variable.

\section{Results and Discussion}

Table 1clearly shows non-significant differences in the serum levels of both T4 and TSH between the bodybuilder athletes $(90.18 \pm 4.31$ and $95.28 \pm 6.97$, respectively) and the control group (2.06 \pm .20 and $2.70 \pm 0.32$, respectively).However, T3 level was significantly different $(\mathrm{p} \leq 0.05)$ between the bodybuilder athletes $(1.70 \pm 0.06)$ and control group $(2.54 \pm 0.15)$.

Table 1- Distribution of mean levels of thyroid hormones in bodybuilder athletes and control group

\begin{tabular}{|c|c|c|c|}
\hline \multirow{2}{*}{ Parameter } & \multicolumn{2}{|c|}{ Mean $\pm \mathrm{SE}$} & \multirow{2}{*}{-value } \\
\cline { 2 - 3 } & bodybuilder athletes & Control group & 0.0001 \\
\hline $\mathrm{T} 3(\mathrm{nmole} / \mathrm{L})$ & $1.70 \pm 0.06$ & $2.54 \pm 0.15$ & 0.570 \\
\hline $\mathrm{T} 4(\mathrm{nmole} / \mathrm{L})$ & $90.18 \pm 4.31$ & $95.28 \pm 6.97$ & 0.367 \\
\hline $\mathrm{TSH}(\mu \mathrm{IU} / \mathrm{I})$ & $2.06 \pm .20$ & $2.70 \pm .32$ & \\
\hline
\end{tabular}

Exercise is described as a form of physical stress that is accompanied by a series of physiological changes to counteract the impact on endocrine and metabolic processes [24]. The impact of exercise on thyroid function is debatable. However, this impact tends to depend on the intensity and length of the workout [25]. Our results are in agreement with those of Pakarinen et al. (1988) who observed no change in T3 after resistance exercise. On the other hand, the current results are not in harmony with another study that showed a substantial decrease in the levels of bound and free T4 [26]. During resistance exercise, Simsch et al. (2002) observed a drop in free T3 and TSH levels, but no substantial change in T4 [27]. Pakarinen et al. (1991) observed a substantial decline in T3, T4, and TSH in advanced weightlifters after a week of concentrated resistance exercise (two sessions per day) [28]. Similarly, after a week of intense strength training (two sessions per day), professional weightlifters showed a substantial drop in T3, T4, and TSH, according to Alen et al. (1993) [29]. Resistance exercise has been found to be pretentious to thyroid function [30].

Table 2 shows a significant decrease in the baseline FSH and testosterone levels in bodybuilder athletes when compared with the control group ( $p<0.0001)$. At the same time, LH level was found to be significantly decreased in bodybuilder athletes than the control group. 
Table 2- Distribution of mean serum levels of gonadotropin hormones in bodybuilder athletes and control groups

\begin{tabular}{|c|c|c|c|}
\hline \multirow{2}{*}{ Parameter } & \multicolumn{2}{|c|}{ Mean \pm SE } & \multirow{2}{*}{-value } \\
\cline { 2 - 3 } & Bodybuilder athletes & Control group & 0.001 \\
\hline FSH $(\mathrm{mIU} / \mathrm{mL})$ & $3.02 \pm .34$ & $5.85 \pm .14$ & 0.007 \\
\hline LH $(\mathrm{mIU} / \mathrm{mL})$ & $5.96 \pm .76$ & $8.78 \pm .57$ & 0.001 \\
\hline Testosterone $(\mathrm{ng} / \mathrm{ml})$ & $1.03 \pm .10$ & $5.48 \pm .23$ & \\
\hline
\end{tabular}

These results are similar to the observations of a number of other investigators. Mandal et al. (2010) showed that exercise, both acute and chronic, is linked to suppressed endocrine functions in the hypothalamus and testes, primarily the suppression of gonadotropin-releasing hormone $(\mathrm{GnRH})$ and serum testosterone [31]. Walker and Cheng (2005) stated that exogenous hormones are also believed to suppress the synthesis of gonadotropin-releasing hormone, which in turn inhibits the release of luteinizing hormones and, as a result, testosterone development [32]. Parkinson and Evans (2006) also confirmed, by an animal model analysis conducted in India, the harmful effects on testes triggered by intraperitoneal injection of AAS. In addition, adverse improvements in the seminiferous epithelium of the testes and tubular diameter reduction were reported, resulting in lower pituitary gonadotropin (LH and FSH) and serum testosterone levels [33].

These symptoms are caused by the fact that elevated doses of AAS derivatives trigger negative feedback on the hypothalamic pituitary axis, lowering LH and FSH secretion. The activity of intratesticular testosterone and FSH on Sertoli cells is needed for spermatogenesis. Only Sertoli cells in the seminiferous tubules have FSH and testosterone receptors. When FSH binds to FSH receptors on these cells, it activates a cascade of signaling pathways that work in tandem with testosterone to boost spermatogenesis and fertility [34]. To show the net and independent effects of a set of explanatory variables on baseline serum testosterone level, multiple linear regression model was used [35]. The multiple linear regression equation used in this model is:

$y \mathbf{i}=\beta 0+\beta 1 \times i 1+\beta 2 \times i 2+\ldots+\beta p \times i p+\epsilon$

In the first step, all the possible explanatory variables were entered in the model and the resulting equation is shown in Table 3. A positive correlation was observed between the serum levels of FSH, total cholesterol, triglyceride and the outcome variable (testosterone). A negative correlation was observed between HDL level, age, and mean serum testosterone level. The resulting differences obtained from the equation were statistically significant $(\mathrm{P}<0.05)$ and explained $0.99 \%$ of the observed variation in the dependent variable.

To recover their athletic performance, some athletes take anabolic steroids, which are synthetic versions of testosterone [36]. Anabolic steroid use has been connected to a variety of negative consequences, including an elevated risk of cardiovascular disease [37]. Crosssectional results support the hypothesis that anabolic steroids use in athletes lowers HDL-C and raises LDL-C levels in the blood [38], and this may be linked to acute myocardial infarction [39] or ischemic stroke [40]. There is, still, no long-term research on the effects of anabolic steroids on lipids. 
Table 3-Multiple linear regression equation with testosterone level as the dependent variable and the studied independent variables

\begin{tabular}{|c|c|c|c|c|c|c|c|}
\hline \multirow{2}{*}{ Model } & \multicolumn{2}{|c|}{$\begin{array}{l}\text { Unstandardized } \\
\text { Coefficients }\end{array}$} & \multirow{2}{*}{$\begin{array}{c}\begin{array}{c}\text { Standardized } \\
\text { Coefficients }\end{array} \\
\boldsymbol{\beta}\end{array}$} & \multirow{2}{*}{ Sig. } & \multicolumn{3}{|c|}{ Correlations } \\
\hline & $\mathbf{B}^{*}$ & Std. Error & & & Zero-order & Partial & Part \\
\hline Age (years) & -.007 & 0.007 & -0.10 & 0.03 & 0.01 & -0.72 & -0.03 \\
\hline T3(nmole/L) & 1.52 & 0.39 & 1.08 & 0.16 & -0.01 & 0.96 & 0.14 \\
\hline T4(nmole/L) & 0.004 & 0.002 & 0.18 & 0.28 & 0.38 & 0.90 & 0.07 \\
\hline TSH $(\mu \mathrm{IU} / \mathrm{I})$ & 0.28 & 0.07 & 0.72 & 0.15 & -0.26 & 0.97 & 0.14 \\
\hline $\mathrm{FSH}(\mathrm{mIU} / \mathrm{mL})$ & 0.53 & 0.07 & 2.25 & 0.05 & 0.35 & 0.99 & 0.25 \\
\hline $\mathrm{LH}(\mathrm{mIU} / \mathrm{mL})$ & 0.06 & 0.01 & 0.56 & 0.13 & 0.65 & 0.97 & 0.16 \\
\hline Cholesterol & 0.013 & 0.002 & 1.00 & 0.01 & 0.27 & 0.98 & 0.20 \\
\hline Triglyceride & -0.009 & 0.001 & 1.04 & 0.05 & 0.43 & 0.98 & 0.19 \\
\hline HDL & 0.04 & 0.009 & -1.45 & 0.01 & 0.16 & -0.99 & -0.44 \\
\hline LDL & 0.74 & 0.13 & 0.39 & 0.11 & 0.17 & 0.98 & 0.19 \\
\hline VLDL & 0.02 & 0.01 & 0.55 & 0.31 & -.53 & 0.87 & 0.06 \\
\hline
\end{tabular}

$* \beta$ :Regression coefficients; $P($ model $)<0.05 ; R^{2}=0.99$;

\section{Conclusion}

The current study shows that excessive bodybuilding exercise has an impact on the HPT axis in top-level athletes. Simultaneous application of anabolic steroids induces major changes in the HPGA axis which regulates testosterone.

\section{References}

[1] J. G. Edwards, J. J. Bahl, I. L. Flink, S. Y. Cheng, and E. Morkin, "Thyroid Hormone Influences Beta Myosin Heavy Chain ( $\beta \mathrm{MHC}$ ) Expression," Biochemical and Biophysical Research Communications, vol. 199, no. 3, pp. 1482-1488, 1994.

[2] E.A.Reyam, Q.A.Makarim "Anti-Mullerian Hormone and Follicle Stimulating Hormone as Markers of Ovarian Agingin a Sample of Iraqi Women" Iraqi Journal of Science, Vol. 57, No.3A, pp.1671-1679,2016.

[3] S.S Sama, H.Y.Jabbar and J.A.Ali"Evaluation of Thyroid Hormones and Some Biochemical Variables in Patients with Chronic Kidney Disease" Iraqi Journal of Science, Vol. 61, No. 5, pp.985-992,2020.

[4] K. E. Friedl, R. J. Moore, R. W. Hoyt, L. J. Marchitelli, L. E. Martinez-Lopez, and E. W. Askew, "Endocrine markers of semistarvation in healthy lean men in a multistressor environment," (in eng), J Appl Physiol, vol. 88, no. 5, pp. 1820-30, 2000.

[5] A. Urhausen, H. Gabriel, and W. Kindermann, "Blood hormones as markers of training stress and overtraining," (in eng), Sports Med, vol. 20, no. 4, pp. 251-76, 1995.

[6] B. C. Nindl, B. R. Barnes, J. A. Alemany, P. N. Frykman, R. L. Shippee, and K. E. Friedl, "Physiological consequences of U.S. Army Ranger training," (in eng), Med Sci Sports Exerc, vol. 39, no. 8, pp. 1380-7, 2007.

[7] N. Cano Sokoloff, M. Misra, and K. E. Ackerman, "Exercise, Training, and the HypothalamicPituitary-Gonadal Axis in Men and Women," (in eng), Frontiers of hormone research, vol. 47, pp. 27-43, 2016.

[8] W. Daly, C. A. Seegers, D. A. Rubin, J. D. Dobridge, and A. C. Hackney, "Relationship between stress hormones and testosterone with prolonged endurance exercise," (in eng), Eur J Appl Physiol, vol. 93, no. 4, pp. 375-80, 2005. 
[9] B. C. Nindl et al., "Testosterone responses after resistance exercise in women: influence of regional fat distribution," (in eng), Int J Sport Nutr Exerc Metab, vol. 11, no. 4, pp. 451-65, 2001.

[10] H. Kumagai, A. Zempo-Miyaki, T. Yoshikawa, T. Tsujimoto, K. Tanaka, and S. Maeda, "Increased physical activity has a greater effect than reduced energy intake on lifestyle modification-induced increases in testosterone," Journal of Clinical Biochemistry and Nutrition, vol. 58, no. 1, pp. 84-89, 2016.

[11] L. Della Guardia, M. Cavallaro, and H. Cena, "The risks of self-made diets: the case of an amateur bodybuilder," Journal of the International Society of Sports Nutrition, vol. 12, no. 1, p. $16,2015$.

[12] P. Gentil et al., "Nutrition, Pharmacological and Training Strategies Adopted by Six Bodybuilders: Case Report and Critical Review," European journal of translational myology, vol. 27, no. 1, p. 6247Accessed on: 2017.

[13] P. J. Perry, B. C. Lund, M. J. Deninger, E. C. Kutscher, and J. Schneider, "Anabolic steroid use in weightlifters and bodybuilders: an internet survey of drug utilization," (in eng), Clin J Sport Med, vol. 15, no. 5, pp. 326-30, 2005.

[14] S. Bhasin, L. Woodhouse, and T. W. Storer, "Proof of the effect of testosterone on skeletal muscle," (in eng), J Endocrinol, vol. 170, no. 1, pp. 27-38, 2001.

[15] J. R. Hoffman and N. A. Ratamess, "Medical issues associated with anabolic steroid use: are they exaggerated?," (in eng), Journal of sports science \& medicine, vol. 5, no. 2, pp. 182-193, 2006.

[16] C.C Allain, L.S. Poon, C.S.Chan, W.F. Richmond, P.C.Fu " Enzymatic determination of total serum cholesterol " Clin Chem. vol.20,no.4,PP. 470-475,1974.

[17] P.Fossati, L.Prencipe " Serum triglycerides determined colorimetrically with an enzyme that produces hydrogen peroxide " Clin Chem,vol. 28,no.10,pp.2077-2080,1982.

[18] R.A.Yeates, T.Mannik, G.D.Calvert " The measurement of plasma-HDL-cholesterol by precipitation techniques " Pathology,vol.11,no.2,pp.324,1979.

[19] W.T. Friedewald's, R.I. Levy, D.S. Fredrickson " Estimation of the concentration of low-density lipoprotein cholesterol in plasma, without use of the preparative ultracentrifuge"Clin Chem. vol,18,no.6,pp.499-502,1972.

[20] J.C.Agharanya, "Clinical usefulness of ELISA technique in the assessment of thyroiid function"West Afr. J. Med., vol.9,no.4,PP. 258-63,1990.

[21] M.Benkirane, et al., J.Immunol.Meth. vol.,98,no.173, 1987.

[22] k.Morimoto, and k.a.Inouye, "ensitive enzyme immunoassay of human thyroid-stimulating hormone ( $\mathrm{LH})$ using bispecific $\mathrm{F}(\mathrm{ab} \phi) 2$ fragments recognizing polymerized alkaline phosphatase and LH". J. Immunol Method, vol. 205 ,no .1,pp.81-90,1997.

[23] M. Uotila, E. Ruoslahti. and E.J.Engvall "Immunol. Methods "vol.42,no.11,1981.

[24] G. Mastorakos and M. Pavlatou, "Exercise as a stress model and the interplay between the hypothalamus-pituitary-adrenal and the hypothalamus-pituitary-thyroid axes," (in eng), Horm Metab Res, vol. 37, no. 9, pp. 577-84, 2005.

[25] J. K. Rone, R. F. Dons, and H. L. Reed, "The effect of endurance training on serum triiodothyronine kinetics in man: physical conditioning marked by enhanced thyroid hormone metabolism," (in eng), Clin Endocrinol (Oxf), vol. 37, no. 4, pp. 325-30, 1992.

[26] A. Pakarinen, M. Alén, K. Häkkinen, and P. Komi, "Serum thyroid hormones, thyrotropin and thyroxine binding globulin during prolonged strength training," European Journal of Applied Physiology and Occupational Physiology, vol. 57, no. 4, pp. 394-398, 1988.

[27] C. Simsch et al., "Training intensity influences leptin and thyroid hormones in highly trained rowers," (in eng), Int J Sports Med, vol. 23, no. 6, pp. 422-7, 2002.

[28] M. Alén, A. Pakarinen, and K. Häkkinen, "Effects of prolonged training on serum thyrotropin and thyroid hormones in elite strength athletes," (in eng), J Sports Sci, vol. 11, no. 6, pp. 493-7, 1993.

[29] U. M. Kujala, M. Alen, and I. T. Huhtaniemi, "Gonadotrophin-releasing hormone and human chorionic gonadotrophin tests reveal that both hypothalamic and testicular endocrine functions are suppressed during acute prolonged physical exercise," (in eng), Clin Endocrinol (Oxf), vol. 33, no. 2, pp. 219-25, 1990.

[30] A. M. Isidori et al., "Effects of testosterone on sexual function in men: results of a meta-analysis," (in eng), Clin Endocrinol (Oxf), vol. 63, no. 4, pp. 381-94, 2005. 
[31] T. K. Mandal and N. S. Das, "Testicular toxicity in cannabis extract treated mice: association with oxidative stress and role of antioxidant enzyme systems," (in eng), Toxicol Ind Health, vol. 26, no. 1, pp. 11-23, 2010.

[32] W. H. Walker and J. Cheng, "FSH and testosterone signaling in Sertoli cells," (in eng), Reproduction, vol. 130, no. 1, pp. 15-28, 2005.

[33] A. B. Parkinson and N. A. Evans, "Anabolic androgenic steroids: a survey of 500 users," (in eng), Med Sci Sports Exerc, vol. 38, no. 4, pp. 644-51, 2006.

[34] P. Vanberg and D. Atar, "Androgenic anabolic steroid abuse and the cardiovascular system," (in eng), Handb Exp Pharmacol, no. 195, pp. 411-57, 2010.

[35] Biostatistics: Basic Concepts \& Methodology for the Health Sciences. WW Daniel; $9^{\text {th }}$ ed. John Wiley \& Sons Inc. 2010.

[36] G. Glazer, "Atherogenic Effects of Anabolic Steroids on Serum Lipid Levels: A Literature Review," Archives of Internal Medicine, vol. 151, no. 10, pp. 1925-1933, 1991.

[37] K. Stergiopoulos, J. J. Brennan, R. Mathews, J. F. Setaro, and S. Kort, "Anabolic steroids, acute myocardial infarction and polycythemia: a case report and review of the literature," (in eng), Vasc Health Risk Manag, vol. 4, no. 6, pp. 1475-80, 2008.

[38] R. D. Santamarina, A. G. Besocke, L. M. Romano, P. L. Ioli, and S. E. Gonorazky, "Ischemic stroke related to anabolic abuse," (in eng), Clin Neuropharmacol, vol. 31, no. 2, pp. 80-5, 2008.

[39] J. C. Perry, T. M. Schuetz, M. D. Memon, S. Faiz, and I. Cancarevic, "Anabolic Steroids and Cardiovascular Outcomes: The Controversy," (in eng), Cureus, vol. 12, no. 7, pp. e9333-e9333, 2020.

[40] R. M. Shamloul, A. F. Aborayah, A. Hashad, and F. Abd-Allah, "Anabolic steroids abuse-induced cardiomyopathy and ischaemic stroke in a young male patient," (in eng), BMJ case reports, 2014. 